\title{
Nivolumab in pre-treated advanced non-small cell lung cancer: long term follow up data from the Dutch expanded access program and routine clinical care
}

\author{
Robert D. Schouten ${ }^{1}$, Lucie Egberink ${ }^{1}$, Mirte Muller ${ }^{1}$, Cornedine J. De Gooijer ${ }^{1}$, Erik van Werkhoven ${ }^{2}$, \\ Michel M. van den Heuvel ${ }^{3}$, Paul Baas ${ }^{1,4}$ \\ ${ }^{1}$ Department of Thoracic Oncology, ${ }^{2}$ Department of Biometrics, Netherlands Cancer Institute, Amsterdam, The Netherlands; ${ }^{3}$ Department of \\ Respiratory Medicine, Radboud University Medical Centre, Nijmegen, The Netherlands; ${ }^{4}$ Department of Pulmonology, Leiden University Medical \\ Centre, Leiden, The Netherlands \\ Contributions: (I) Conception and design: RD Schouten, P Baas; (II) Administrative support: L Egberink, M Muller, CJ De Gooijer, E van \\ Werkhoven; (III) Provision of study materials or patients: P Baas, MM van den Heuvel; (IV) Collection and assembly of data: RD Schouten, L \\ Egberink, M Muller, CJ De Gooijer; (V) Data analysis and interpretation: RD Schouten, P Baas, MM van den Heuvel, E van Werkhoven; (VI) \\ Manuscript writing: All authors; (VII) Final approval of manuscript: All authors. \\ Correspondence to: Robert D. Schouten. Department of Thoracic Oncology, Netherlands Cancer Institute, Plesmanlaan 121, 1066 CX Amsterdam, \\ The Netherlands. Email: rd.schouten@nki.nl.
}

Background: For advanced non-small cell lung cancer anti-PD-1 treatment has become standard care in first and second line treatment in recent years. Because many of the clinical trials with anti-PD-1 drugs have only recently been completed, long term follow up data of patients treated with these agents is scarce, even more so of patients treated in real life clinical care. We present long term follow up of patients treated with nivolumab.

Methods: Two hundred forty-eight patients with pre-treated, advanced NSCLC who received nivolumab between August 2015 and December 2018 were included in this retrospective cohort study. Overall survival and progression free survival rates were calculated for the total cohort and for subgroups defined by clinical characteristics, responses to treatment, and other parameters. Data on further lines of treatment and characteristics of long term survivors were also collected.

Results: Median overall survival in the total cohort was 8.1 months, median progression free survival was 2.8 months. Overall survival after two and three years was $23.8 \%$ and $17.1 \%$, respectively. Good ECOG performance scores, absence of liver metastases, experiencing treatment-related toxicity, and response to nivolumab were significantly associated with longer overall survival and progression free survival. Three-year survival rate among patients with an objective response was $55.3 \%$. Survival for more than two years without subsequent therapy after nivolumab was observed in $13.3 \%$ of patients.

Conclusions: The results from our study confirm that long term survival rates of patients treated with nivolumab for advanced NSCLC in a real world clinical setting are comparable to survival rates shown in clinical trials.

Keywords: Long term follow up; nivolumab; non-small cell lung carcinoma; real world

Submitted Dec 20, 2019. Accepted for publication Jul 09, 2020.

doi: $10.21037 /$ tlcr-19-698

View this article at: http://dx.doi.org/10.21037/tlcr-19-698 


\section{Introduction}

Following multiple large clinical trials (1-5), checkpoint inhibitors have become the new standard of care for patients with advanced non-small cell lung cancer (NSCLC) in first and second line (6). Nivolumab was the first antiPD1 inhibitor with approval for previously treated NSCLC in regular clinical care in 2015. Long term follow up of patients treated with these agents is still scarce and is mainly derived from clinical trials (7-9). Data from real world clinical practice can be of additional value (10), as it provides insight in the effectiveness of these new agents in a more diverse group of patients (11-13).

The Netherlands Cancer Institute (NKI) has published real life experience with nivolumab for the treatment of NSCLC of patients treated between August 2015 and October 2016. In the first eight months of this period nivolumab was provided through an Extended Access Program (EAP). Currently, there are 3 years of follow up for the patients that have been treated in the EAP and 2.5 years of follow up for those treated in regular clinical care. Due to the relative fast reimbursement process and hence patient access in the Netherlands compared to the rest of Europe, follow up in the Netherlands is one of the longest in Europe.

Here we present an update on the previously published patient cohort (13). The primary aim of this study was to provide insight in the long term efficacy of nivolumab in second line treatment for NSCLC in a real life clinical setting, compared to results from clinical trials. Secondly, we aimed to identify characteristics associated with improved outcome in subgroup analyses.

We present the following article in accordance with the STROBE reporting checklist (available at http://dx.doi. org/10.21037/tlcr-19-698).

\section{Methods}

\section{Patients}

All patients who received nivolumab during the EAP in the NKI were included in this retrospective observational cohort study ( $\mathrm{n}=133$ ). Additionally, the first 115 patients that received nivolumab in regular clinical care in the NKI were included. Patients that were registered in the EAP but did not receive nivolumab were excluded.

\section{Analyses of real life data}

All data were retrospectively collected from the electronic medical records. Schedules of treatment, response evaluations and toxicity assessment have been described before (13). Subgroup analyses for progression free survival (PFS) and overall survival (OS) were performed. Descriptions of the 12 subgroups are listed in Table S1 and include demographics, disease characteristics, responses to treatment, and other parameters, e.g., (theoretical) eligibility for CheckMate 017 and 057 studies $(1,2)$. Database was locked on January 1, 2019.

\section{Ethical statement}

This study was conducted in accordance with the Declaration of Helsinki (as revised in 2013) and the guidelines for Good Clinical Practice. Because of the retrospective nature of the research, the requirement for Ethics Board approval and informed consent was waived.

\section{Statistical considerations}

PFS was defined as time between the first dose of nivolumab and disease progression or death. OS was defined as time between first dose and death. PFS and OS were estimated using the Kaplan-Meier method and log-rank tests were performed to compare survival between subgroups. Statistical significance was defined as $\mathrm{P}<0.05$. Hazard ratios and corresponding confidence intervals were calculated with a multivariate Cox proportional hazards model. To increase the prediction accuracy of model we excluded variables from the multivariate analysis for two reasons. Firstly, overlapping variables were excluded, i.e., CheckMate eligibility and inclusion in the EAP (Table S1), as both these variables overlapped by definition with ECOG performance score. Secondly, variables that were not associated with PFS or OS in univariate analysis $(\mathrm{P}>0.05)$ were excluded from the corresponding multivariate analysis. Missing data were excluded by list-wise deletion.

\section{Results}

\section{Patients and treatment}

All 248 included patients started nivolumab treatment between August 6, 2015 and September 21, 2016. Median follow up time was 7.9 months (range, 0-40.7). At the time of database lock 38 patients (15.3\%) were alive, of whom two were still on active treatment with nivolumab. Sixteen patients $(6.5 \%)$ were lost to follow up, and 194 patients 
(78.2\%) died. Cohort characteristics are shown in Table 1.

The median number of cycles of nivolumab per patient was 12 (range, 1-71) and the median duration of treatment was 2.3 months (range, $0-36.8$ ). For 54 patients (21.8\%) survival with available follow up was longer than 2 years. In this group the median number of cycles was 25 and the median duration of treatment was 12.8 months.

\section{Survival}

In the total cohort median OS was 8.1 months, 1-year OS rate was $39.8 \%$, 2-year OS rate was $23.8 \%$, and 3-year OS was $17.1 \%$. Median PFS was 2.8 months, with 1-, 2-, and 3 -year PFS rates of $22.2 \%, 15.7 \%$, and $9.0 \%$, respectively (Figure 1).

Statistically significant differences in both OS and PFS were observed in five subgroups. Variables associated with improved outcomes were: a positive smoking history, ECOG performance score (PS) of 0 or 1 , absence of liver metastases at baseline, objective response (OR) to nivolumab treatment, and experiencing a treatment-limiting toxicity. Additionally, patients who started nivolumab treatment in the EAP had a significantly longer PFS than patients who started in regular clinical care. However, no difference in OS was observed in this subgroup analysis (Figures 2 and 3).

No differences in OS or PFS were observed in subgroups defined by sex, age, tumor histology, or presence of brain metastases $(\mathrm{P}>0.20$ for all). Furthermore, no difference in PFS or OS was observed between patients who would have been eligible for inclusion in CheckMate 017 and 057 studies and patients who were not. Lastly, patients stratified by OR to prior chemotherapy did show a significant difference in PFS or OS following subsequent treatment with nivolumab (Figures $S 1$ and S2).

For the multivariate analyses subsets of variables were selected, according to the criteria described earlier. Consequently, Cox proportional hazards models were fit using the variables listed in Tables 2 and 3. Four variables were consistently associated with improved OS and PFS: ECOG PS of 0 or 1 , absence of liver metastases at baseline, OR to current nivolumab treatment, and experiencing a treatment-limiting toxicity. Notably, although a history of smoking was associated with longer PFS and OS in univariate analyses, this did not remain statistically significant in multivariate analyses.

Response to nivolumab treatment had the strongest correlation with prolonged survival in our cohort. All partial or complete responses to treatment were seen in the first twelve months of treatment. Patients who responded to treatment had an estimated $76.4 \%$ overall survival rate after two years, in contrast to non-responders (2-year OS rate: $8.0 \%)$. OS rates after three years were $55.3 \%$ for responders and $5.5 \%$ for non-responders.

\section{Further lines of treatment}

Following progression after nivolumab 48 patients (19.4\%) received further systemic treatment. In this group, 25 patients received subsequent chemotherapy: 11 had a partial response (PR, 44.0\%), 8 had stable disease (SD, 32.0\%), 1 had progressive disease (PD, $4.0 \%$ ), and 5 had no reported response evaluation $(20.0 \%)$.

Twelve patients switched to targeted therapy, three of whom responded $(25.0 \%)$, six maintained SD (50.0\%), one progressed $(8.3 \%)$ and two patients $(16.7 \%)$ had no reported response evaluation.

Combination immunotherapy was started in seven patients, of whom one had a partial response on nivolumab plus ipilimumab, five patients maintained SD and one progressed after nivolumab plus BMS98615.

Other treatments that were initiated after nivolumab were bevacizumab monotherapy (two patients with SD), and paclitaxel plus trastuzumab (one patient, PD). Lastly, one patient was retreated with nivolumab. This patient's first period of treatment with nivolumab was from December 2015 until April 2016, during which a partial response was radiologically confirmed twice. At the patient's request, treatment was stopped and during a 4-month period of watchful waiting an ongoing response was radiologically confirmed in June and August 2016. Follow up was subsequently lost for two years, after which the patient revisited the NKI with disease progression in September 2018. Because of the initial response and because nivolumab was well tolerated, it was reinitiated. However, there was no response to retreatment and progression was confirmed in October 2018. At the last date of follow up in December 2018 the patient was alive without subsequent therapy.

\section{Patients without progression after 2 years}

Out of 248 patients, 33 patients (13.3\%) were alive for longer than 2 years without subsequent treatment after nivolumab. Thirty-one patients were alive at time of database lock, one patient died after 30.7 months, another after 26.8 months after initiation of nivolumab treatment. 
Table 1 Patient characteristics. Total size of the cohort was 248 patients. Numbers indicate absolute number of patients in the subgroups and corresponding percentages of the total cohort, unless stated otherwise

\begin{tabular}{|c|c|c|}
\hline Characteristics & $\mathrm{N}$ & $\%$ \\
\hline \multicolumn{3}{|l|}{ Sex } \\
\hline Male & 136 & 54.8 \\
\hline Female & 122 & 45.2 \\
\hline \multicolumn{3}{|l|}{ Age } \\
\hline Mean (years) & 63 & \\
\hline 65 or older & 108 & \\
\hline 64 or younger & 140 & \\
\hline \multicolumn{3}{|l|}{ Smoking status } \\
\hline Current or former smoker & 200 & 80.7 \\
\hline Pack-years & Median: 30 & Range: 2-96 \\
\hline Never smoker & 44 & 17.7 \\
\hline Unknown & 4 & 1.6 \\
\hline \multicolumn{3}{|l|}{ Tumour histology } \\
\hline Squamous cell carcinoma & 55 & 22.2 \\
\hline Non-squamous & 193 & 77.8 \\
\hline Adenocarcinoma & 165 & 66.5 \\
\hline Mixed or multiple types & 16 & 6.5 \\
\hline Not otherwise specified & 12 & 4.8 \\
\hline \multicolumn{3}{|l|}{ ECOG-PS } \\
\hline 0 & 61 & 24.6 \\
\hline 1 & 147 & 59.3 \\
\hline 2 & 33 & 13.3 \\
\hline$>2$ & 7 & 2.8 \\
\hline \multicolumn{3}{|l|}{ Liver metastases $^{\dagger}$} \\
\hline Present at baseline & 43 & 17.3 \\
\hline Not present at baseline & 205 & 82.7 \\
\hline \multicolumn{3}{|l|}{ Brain metastases $^{\dagger}$} \\
\hline Present at baseline & 56 & 22.6 \\
\hline Not present at baseline & 192 & 77.4 \\
\hline \multicolumn{3}{|l|}{ First access to nivolumab } \\
\hline Expanded Access Program & 133 & 53.6 \\
\hline Regular clinical care & 115 & 46.4 \\
\hline \multicolumn{3}{|l|}{ 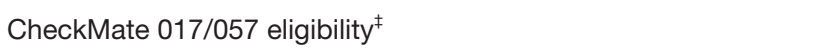 } \\
\hline One or more exclusion criteria & 150 & 60.5 \\
\hline No exclusion criteria & 98 & 39.5 \\
\hline
\end{tabular}

Table 1 (continued)

\begin{tabular}{|c|c|c|}
\hline Characteristics & $\mathrm{N}$ & $\%$ \\
\hline \multicolumn{3}{|l|}{ Response to prior chemotherapy ${ }^{\S}$} \\
\hline Objective responders & 65 & 26.2 \\
\hline Partial response & 65 & 26.2 \\
\hline Non-responders & 124 & 50.0 \\
\hline Stable disease & 51 & 20.6 \\
\hline Progressive disease & 73 & 29.4 \\
\hline Unknown & 58 & 23.4 \\
\hline \multicolumn{3}{|l|}{ Response to nivolumab ${ }^{\S}$} \\
\hline Objective responders & 57 & 23.0 \\
\hline Complete response & 1 & 0.4 \\
\hline Partial response & 56 & 22.6 \\
\hline Non-responders & 191 & 77.0 \\
\hline Stable disease & 53 & 21.4 \\
\hline Progressive disease & 115 & 46.4 \\
\hline $\begin{array}{l}\text { Died before first response } \\
\text { evaluation }\end{array}$ & 23 & 9.3 \\
\hline \multicolumn{3}{|l|}{ Treatment-limiting toxicity" } \\
\hline $\begin{array}{l}\text { Toxicity leading to discontinuation } \\
\text { of nivolumab }\end{array}$ & 21 & 8.5 \\
\hline $\begin{array}{l}\text { No toxicity leading to } \\
\text { discontinuation }\end{array}$ & 227 & 91.5 \\
\hline \multicolumn{3}{|l|}{ Number of prior lines of treatment } \\
\hline 0 & 2 & 0.80 \\
\hline 1 & 185 & 74.60 \\
\hline 2 & 44 & 17.7 \\
\hline 3 & 14 & 5.7 \\
\hline$>3$ & 3 & 1.2 \\
\hline \multicolumn{3}{|c|}{$\begin{array}{l}{ }^{\dagger} \text {, patients with radiologically proven liver or brain metastases } \\
\text { before the start of nivolumab treatment. }{ }^{\ddagger} \text {, patients were } \\
\text { retrospectively screened for in- and exclusion criteria for } \\
\text { the CheckMate } 017 \text { and } 057 \text { trials, solely for the purpose } \\
\text { of our study, not for actual trial participation. }{ }^{\S} \text {, response to } \\
\text { chemotherapy prior to initiation of nivolumab treatment was } \\
\text { based in physician reported outcomes, response to nivolumab } \\
\text { was based on RECIST criteria, applied by the treating physician; } \\
\text { ", a subgroup of } 21 \text { patients experienced nivolumab-related } \\
\text { severe adverse events leading to discontinuation of the } \\
\text { treatment, patients that experienced (serious) adverse events } \\
\text { not leading to discontinuation were included in the 'no toxicity } \\
\text { leading to discontinuation' group. }\end{array}$} \\
\hline
\end{tabular}

Table 1 (continued) 

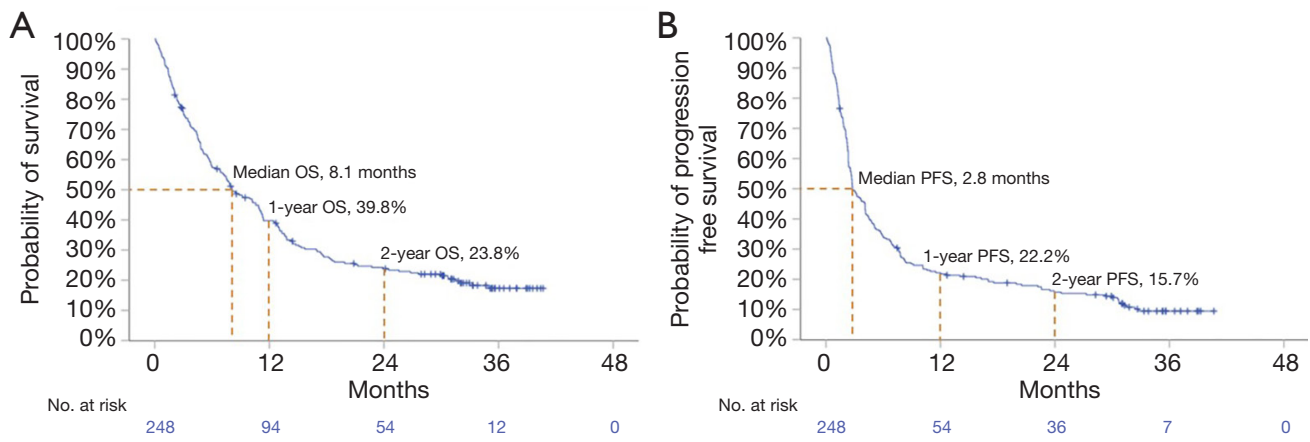

Figure 1 Survival data from the total cohort. Median, 1-year, and 2-year OS and PFS are shown in the figures. 3-year OS and PFS are not shown due to low numbers of patients at risk at that timepoint. (A) Overall survival in the total cohort. (B) Progression free survival in the total cohort.

Characteristics and follow up of these patients are shown in Table 4 and Figure 4.

Median age was 64 years (range, 49-81), 17 were male (51.5\%), 24 (72.7\%) had non-squamous NSCLC. Smoking status was unknown for 2 patients, 29 (87.9\%) were (former) smokers. ECOG-PS was $0(n=12), 1(n=17)$ or $2(n=4)$ on the day of treatment initiation. One patient achieved complete response, eight patients maintained stable disease for the duration of treatment and follow up and 24 patients had a partial response to nivolumab. Median number of cycles in this group was 24 (range, 1-63) and median duration of treatment was 12.4 months (range, 0-36.8).

In this group of long survivors, thirteen patients (39.4\%) discontinued treatment due to toxicity. Grade 3 toxicities were observed in six patients presenting with colitis $(\mathrm{n}=3)$, pancreatitis, hyperglycaemia, and conjunctivitis. Other toxicities reported in this group were lower grade pneumonitis, myositis, arthritis, cystitis and adrenal insufficiency.

\section{Discussion}

Large international studies have shown that immunotherapy can improve survival of advanced NSCLC patients in a clinical trial setting with selected patients $(1-5,14)$. Previous reports on real world data have shown that effectiveness is similar in a clinical setting (11-13). Now that long term data form these clinical studies are published (7-9), a renewed comparison with the real world data can be made.

In this retrospective cohort study of patients with previously treated advanced NSCLC, we found a median overall survival of 8.1 months and a median progression free survival of 2.8 months. OS rates after two and three years were $23.8 \%$ and $17.1 \%$, respectively. These results show that survival rates in our real life cohort were slightly lower than the survival rates found in the pooled cohorts of the CheckMate 017 and 057 studies. Other real world studies have shown similar results $(11,12)$, although follow up in these studies was shorter and data were not fully mature for long term efficacy analysis.

Patients with poorer clinical status may be treated with nivolumab in regular clinical care, in contrast to the clinical trial setting, in which treated patients are much more selected. This may account for the slightly lower rate over OS and PFS in real life. Indeed we found 1- and 2-year OS rates for CheckMate eligible patients of $43.3 \%$ and $26.4 \%$, which are very similar to the long term results of those clinical trials (7-9). In contrast, we did not find a statistically significant difference within our cohort when comparing patient subgroups defined by CheckMate trial eligibility, suggesting that trial results and real life results are indeed comparable.

Further subgroup analyses showed that patients with good ECOG PS have longer OS and PFS. This factor probably contributes to the higher survival rates seen in clinical trials. However, it also indicates that patients with poor ECOG PS are less likely to benefit and starting this treatment should be carefully considered.

In accordance with previous reports $(9,15)$, presence of liver metastases was associated with poor outcomes in our cohort. Moreover, we observed a strong association between the occurrence of adverse events leading to discontinuation of nivolumab treatment and improved outcomes. This phenomenon has been described before and it may be indicative of an enhanced systemic immune activation. It has also been suggested that T-cell targeting of antigens 
A

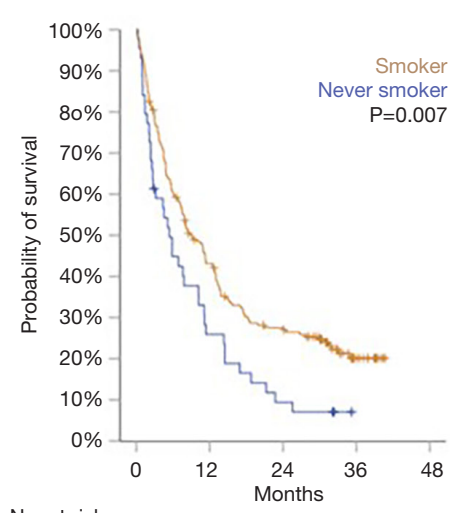

No. at risk

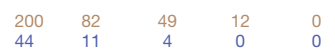

C

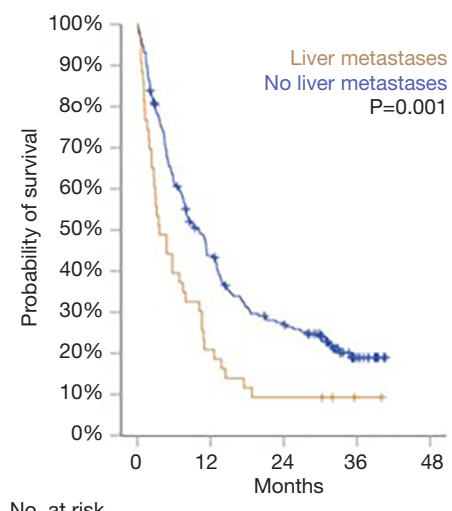

No. at risk $\begin{array}{lcccc}43 & 9 & 4 & 1 & 0 \\ 205 & 85 & 50 & 11 & 0\end{array}$

$E$

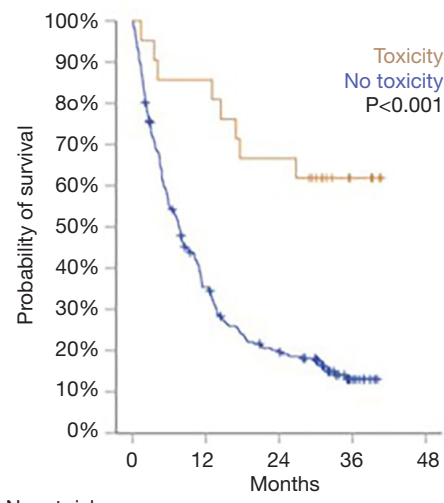

No. at risk

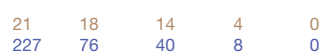

B

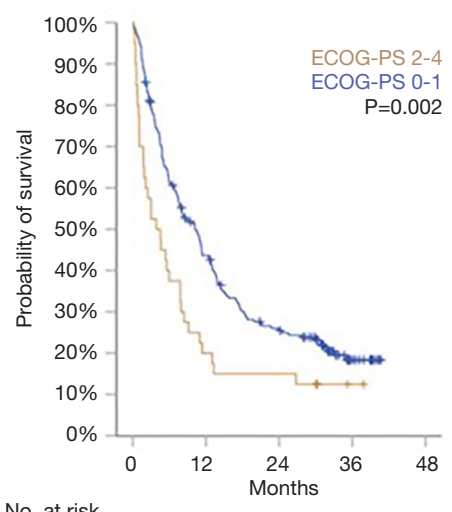

No. at risk $\begin{array}{lcccc}40 & 8 & 6 & 1 & 0 \\ 208 & 86 & 48 & 11 & 0\end{array}$

D

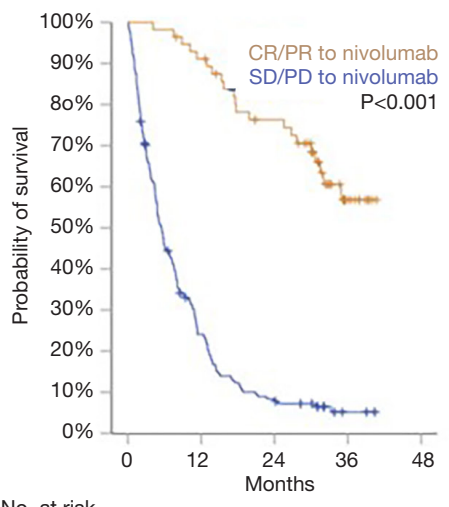

No. at risk $\begin{array}{llccc}57 & 51 & 40 & 10 & 0 \\ 191 & 43 & 14 & 1 & 0\end{array}$

$\mathrm{F}$

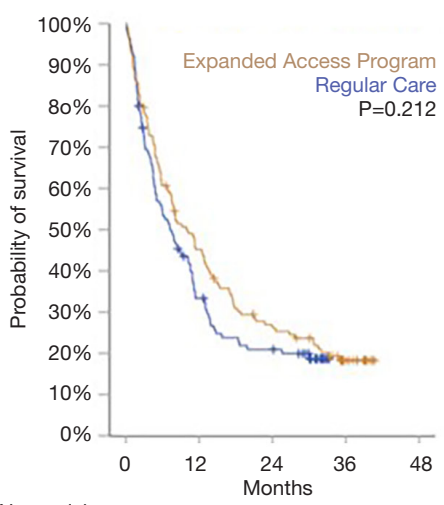

No. at risk

Figure 2 Overall survival of subgroups. Probability of survival for subgroups, estimated by the Kaplan-Meier method. P values and number of patients at risk are shown in the figures. Statistically significantly longer OS was observed in patients with: (A) a history of smoking, (B) an ECOG performance score of 0 or 1 at start of nivolumab treatment, (C) no radiological evidence of liver metastases before start of nivolumab, (D) an objective response to nivolumab treatment, or (E) a nivolumab related serious adverse event leading to discontinuation of treatment. (F) Patients who started nivolumab treatment in the Expanded Access Program did not show longer OS compared to patients who started nivolumab in regular clinical care. 
A

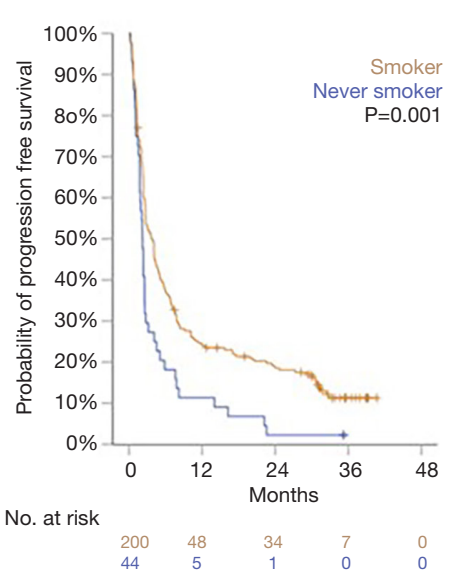

C

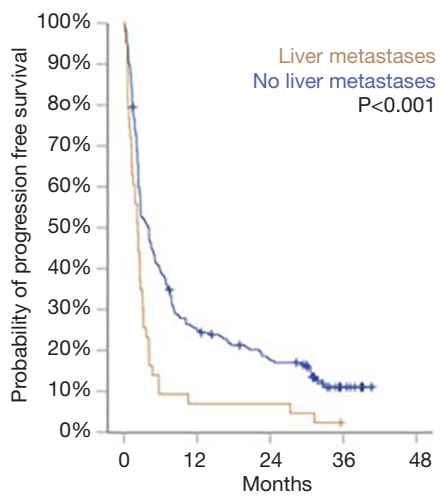

No. at risk

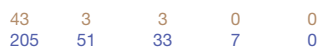

$\mathrm{E}$

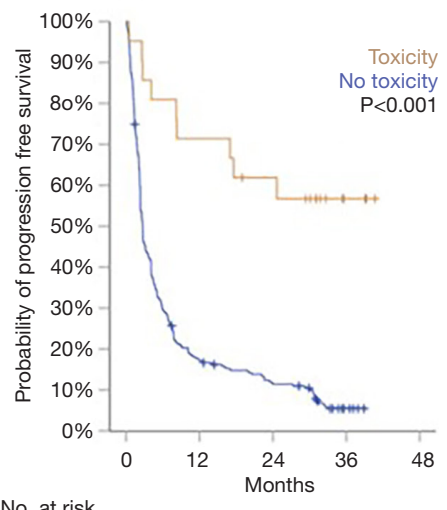

No. at risk

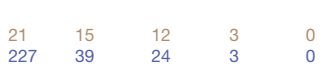

B

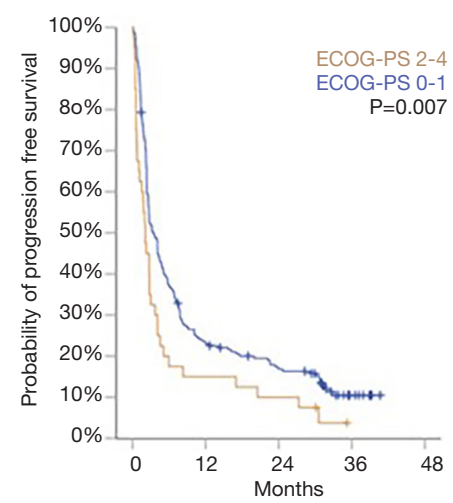

No. at risk
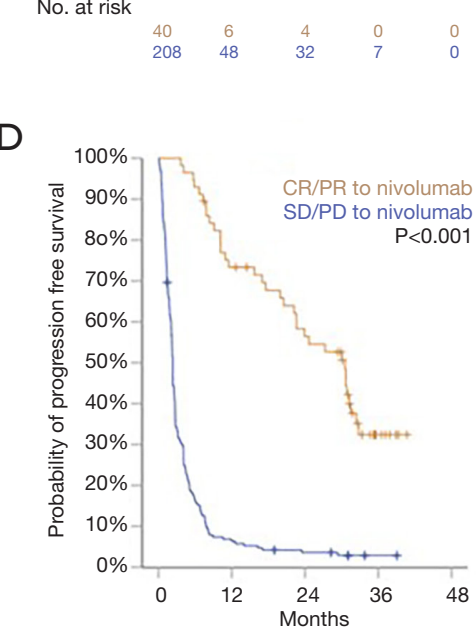

No. at risk

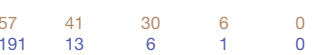

$\mathrm{F}$

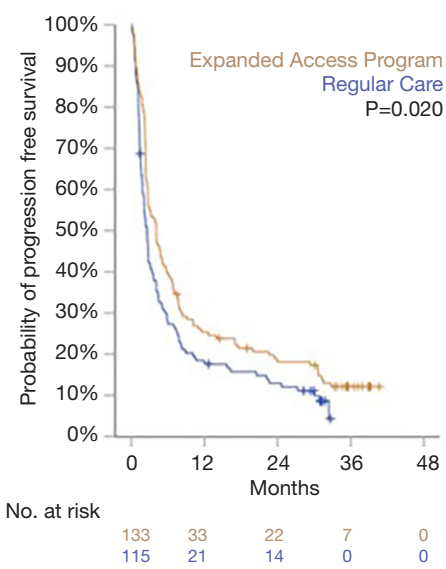

Figure 3 Progression free survival of subgroups. Probability of progression free survival for subgroups, estimated by the Kaplan-Meier method. P values and number of patients at risk are shown in the figures. Statistically significantly longer PFS was observed in patients with: (A) a history of smoking, (B) an ECOG performance score of 0 or 1 at start of nivolumab treatment, (C) no radiological evidence of liver metastases before start of nivolumab, (D) an objective response to nivolumab treatment, or (E) a nivolumab related serious adverse event leading to discontinuation of treatment. Additionally, longer PFS was observed in patients who started nivolumab treatment in the Expanded Access Program compared to patients who started nivolumab in regular clinical care $(\mathrm{F})$. 
Table 2 Impact of variables on overall survival. Median OS and hazard ratios for subgroups, calculated by univariate and multivariate regression analysis

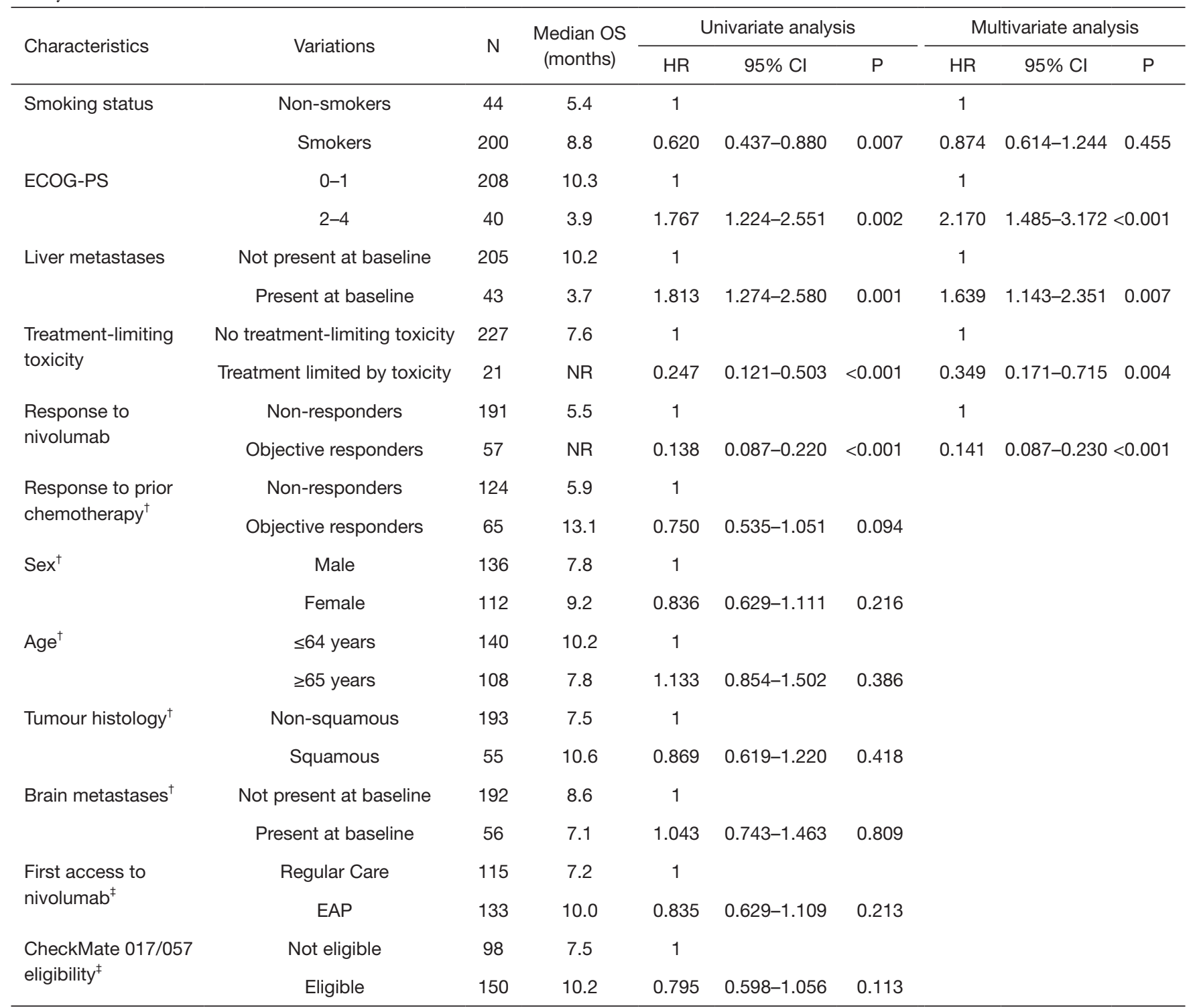

${ }^{\dagger}$, excluded from multivariate analysis because of non-significance in univariate analysis; ${ }^{\ddagger}$, excluded from multivariate analysis because of overlap with other variables, e.g., ECOG-PS by definition. NR, not reached; HR, hazard ratio; Cl, confidence interval.

common to both malignant and healthy cells may lead to adverse effects in normal tissues (16-19).

Additionally, an objective response to nivolumab treatment was strongly related to prolonged survival in our cohort. Three-year OS rate was $55.3 \%$ for patients that responded to nivolumab, tenfold higher than the three-year OS rate in non-responders (5.5\%).

Following progression of disease after nivolumab treatment, approximately $20 \%$ of patients received another systemic treatment. A response rate of $44 \%$ was observed in 25 patients who received subsequent chemotherapy. Other therapies were diverse and effectiveness was limited, as can be expected in third (or more) line of treatment for lung cancer. Notably, retreatment with nivolumab was initiated in one patient with disease progression after initial response. This did not result in a second response, which is 
Table 3 Impact of variables on progression free survival. Median PFS and hazard ratios for subgroups, calculated by univariate and multivariate regression analysis

\begin{tabular}{|c|c|c|c|c|c|c|c|c|c|}
\hline Characteristics & Variations & $\mathrm{N}$ & $\begin{array}{c}\text { Median PFS } \\
\text { (months) }\end{array}$ & \multicolumn{3}{|c|}{ Univariate analysis } & \multicolumn{3}{|c|}{ Multivariate analysis } \\
\hline \multirow[t]{2}{*}{ Smoking status } & Non-smokers & 44 & 2.2 & 1 & & & 1 & & \\
\hline & Smokers & 200 & 3.7 & 0.583 & $0.416-0.818$ & 0.002 & 0.792 & $0.562-1.117$ & 0.184 \\
\hline ECOG-PS & $0-1$ & 208 & 3.5 & 1 & & & 1 & & \\
\hline \multirow[t]{2}{*}{ Liver metastases } & Not present at baseline & 205 & 4.1 & 1 & & & 1 & & \\
\hline & Present at baseline & 43 & 2.3 & 1.908 & $1.357-2.682$ & $<0.001$ & 1.720 & $1.215-2.435$ & 0.002 \\
\hline $\begin{array}{l}\text { Treatment-limiting } \\
\text { toxicity }\end{array}$ & $\begin{array}{l}\text { No treatment-limiting } \\
\text { toxicity }\end{array}$ & 227 & 2.7 & 1 & & & 1 & & \\
\hline $\begin{array}{l}\text { Response to } \\
\text { nivolumab }\end{array}$ & Objective responders & 57 & 30.6 & 0.158 & $0.107-0.233$ & $<0.001$ & 0.159 & $0.106-0.239$ & $<0.001$ \\
\hline \multirow{2}{*}{$\begin{array}{l}\text { Response to prior } \\
\text { chemotherapy }^{\dagger}\end{array}$} & Non-responders & 124 & 2.5 & 1 & & & & & \\
\hline & Objective responders & 65 & 4.1 & 0.836 & $0.606-1.152$ & 0.272 & & & \\
\hline \multirow[t]{2}{*}{$\operatorname{Sex}^{\dagger}$} & Male & 136 & 2.7 & 1 & & & & & \\
\hline & Female & 112 & 3.7 & 0.881 & $0.675-1.151$ & 0.353 & & & \\
\hline $\mathrm{Age}^{\dagger}$ & $\leq 64$ years & 140 & 3.2 & 1 & & & & & \\
\hline \multirow{2}{*}{$\begin{array}{l}\text { First access to } \\
\text { nivolumab }\end{array}$} & Regular Care & 115 & 2.6 & 1 & & & & & \\
\hline & EAP & 133 & 4.1 & 0.730 & $0.559-0.954$ & 0.021 & & & \\
\hline \multirow{2}{*}{$\begin{array}{l}\text { CheckMate 017/057 } \\
\text { eligibility }{ }^{\ddagger}\end{array}$} & Not eligible & 98 & 2.8 & 1 & & & & & \\
\hline & Eligible & 150 & 2.8 & 0.877 & $0.670-1.147$ & 0.337 & & & \\
\hline
\end{tabular}

${ }^{\dagger}$, excluded from multivariate analysis because of non-significance in univariate analysis; ${ }^{\ddagger}$, excluded from multivariate analysis because of overlap with other variables, e.g., ECOG-PS by definition. NR, not reached; HR: hazard ratio; Cl, confidence interval.

in contrast to previously published findings (8).

Survival longer than two years was observed in our cohort in 54 patients $(21.8 \%), 33(13.3 \%)$ of whom received no subsequent treatment after nivolumab. Two patients were treated continuously for over 2.5 years, twelve patients were treated for approximately two years, nine patients were treated for approximately one year and another nine patients were treated with nivolumab for less 
Table 4 Characteristics of long-term survivors. Characteristics of the 33 patients who survived more than two years after initiation of nivolumab without any subsequent treatment

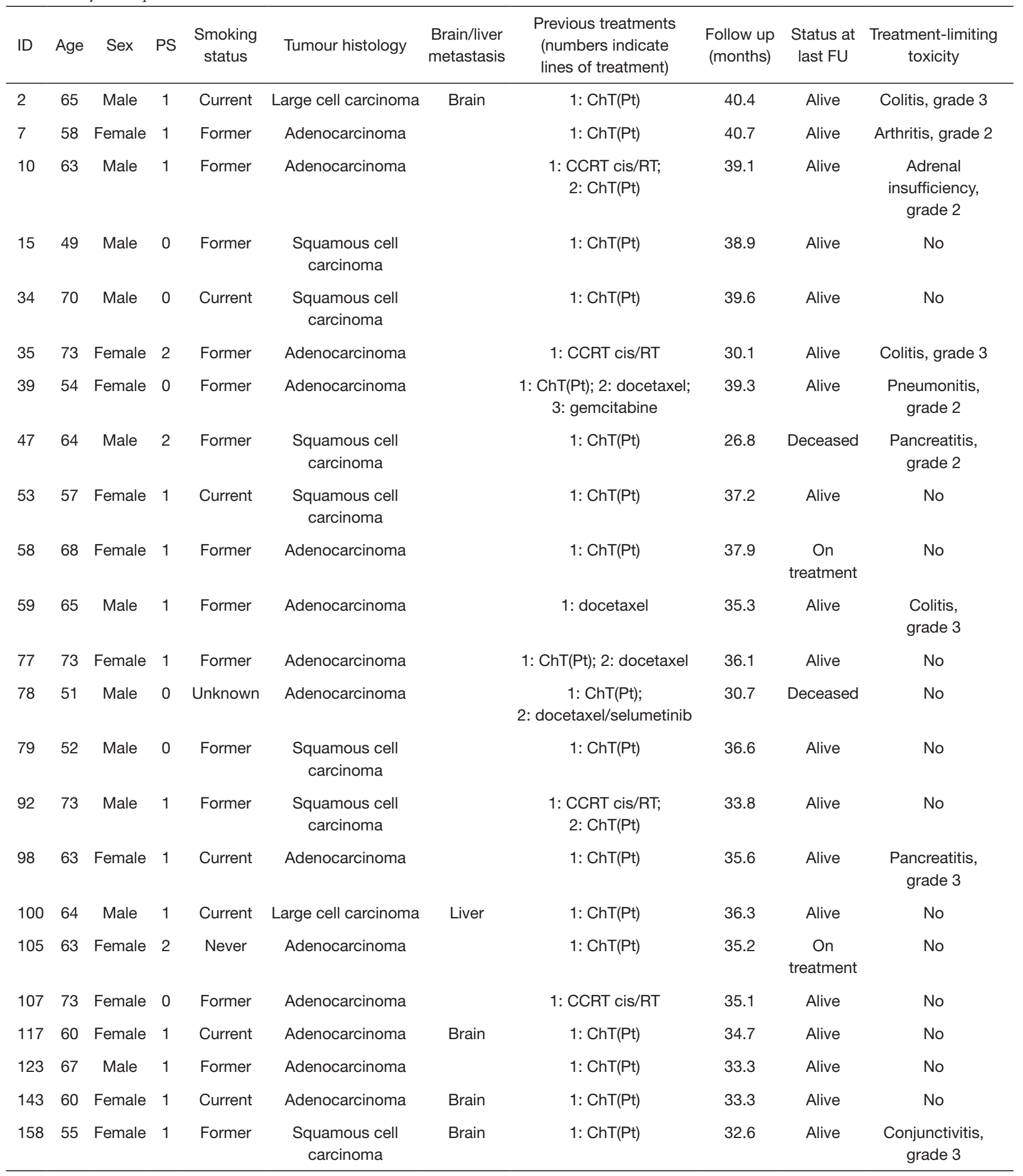

Table 4 (continued) 
Table 4 (continued)

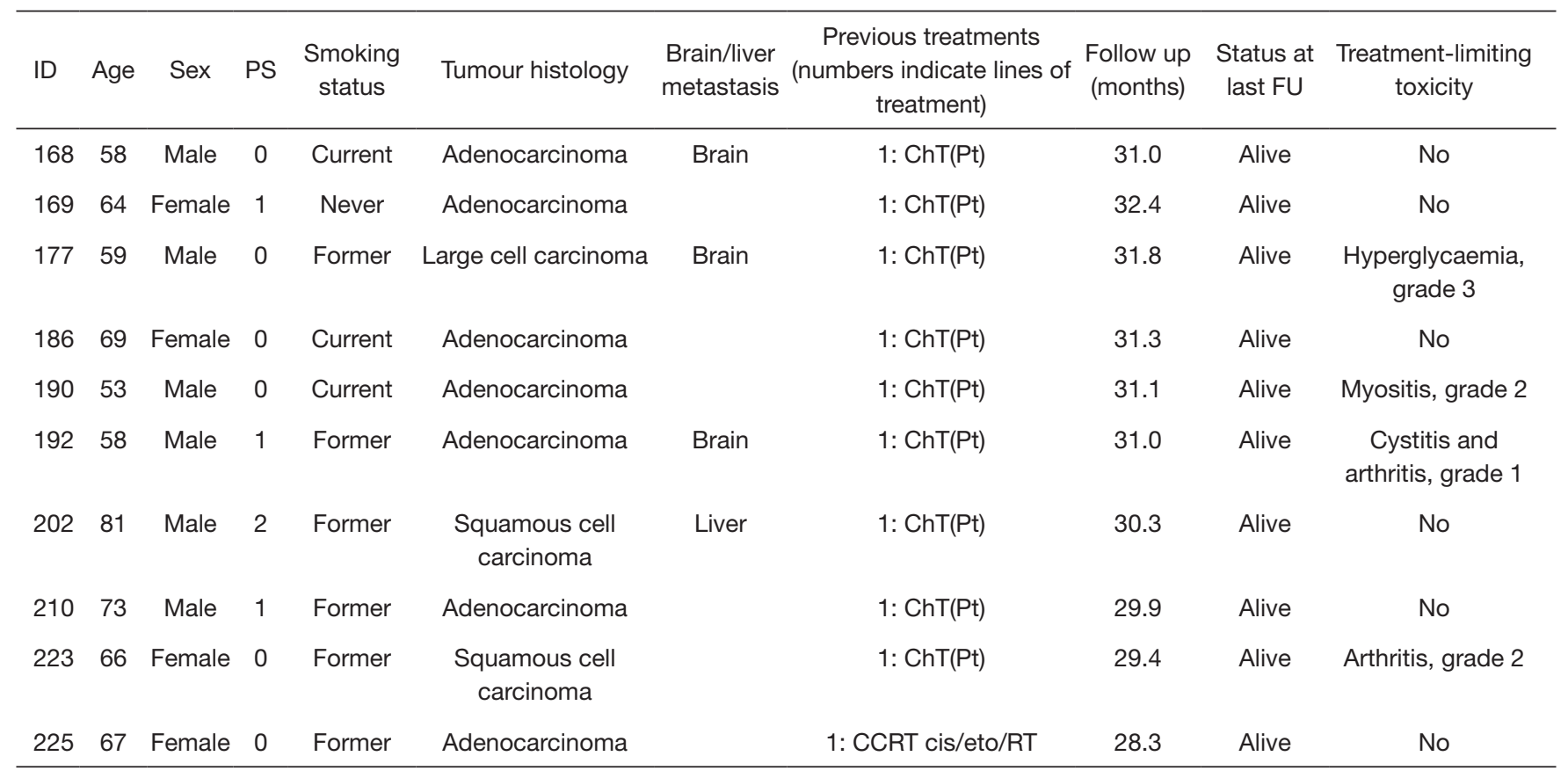

ChT(Pt), platinum-based chemotherapy; PS, ECOG performance status at start of nivolumab treatment; ID, study identification number; cis, cisplatinum; eto, etoposide; RT, radiotherapy; CCRT, concurrent chemoradiotherapy.

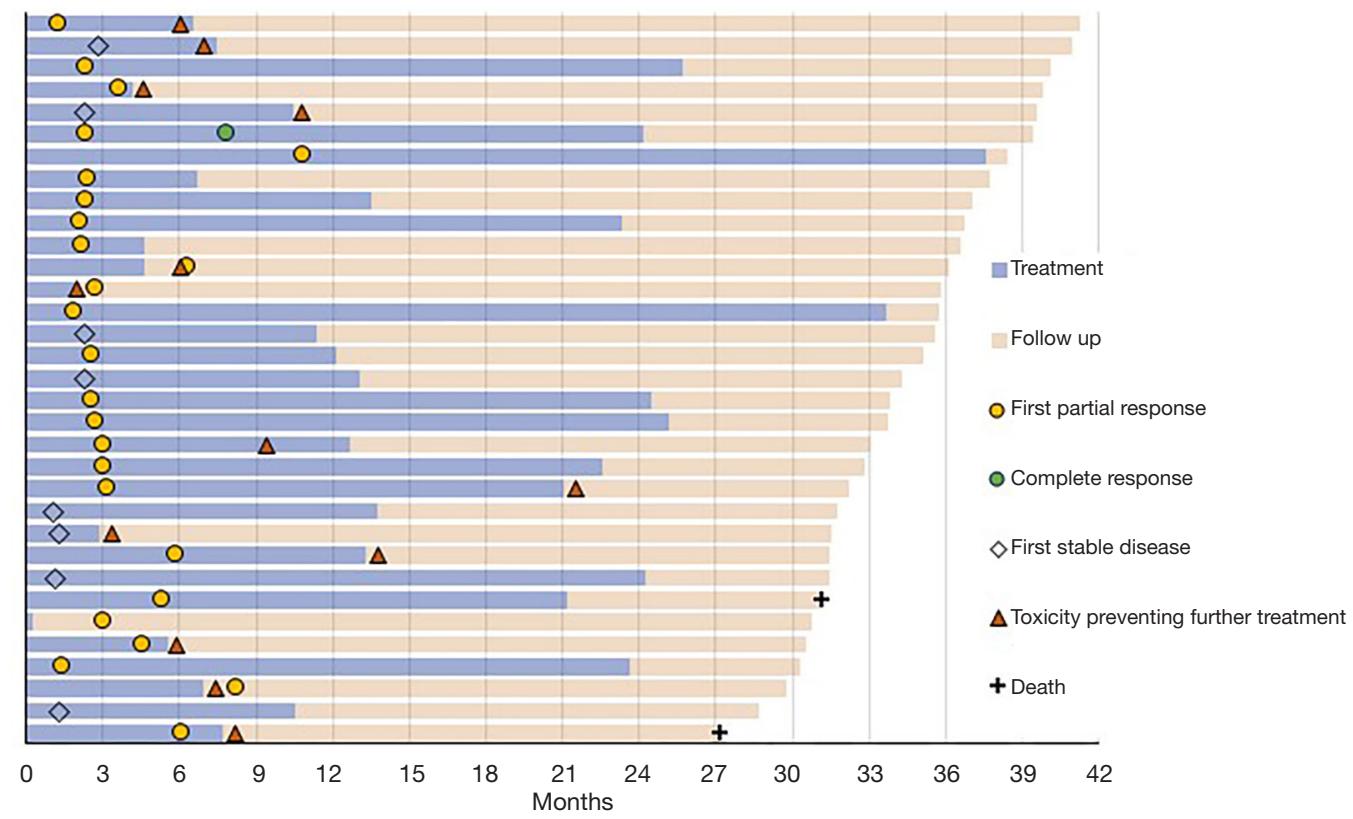

Figure 4 Course of disease of long survivors. Swimmer plot depicting the course of disease of 33 patients with survival of more than two years without subsequent treatment after nivolumab. Duration of treatment was highly variable. Eight patients showed no radiological response, but maintained stable disease for the duration of treatment and follow up. Thirteen out of 33 patients experienced toxicities that ultimately led to discontinuation of treatment. 
than nine months.

Although our large cohort provides rare and valuable data on the long term efficacy of nivolumab in an unselected patient population, the number of patients is still relatively limited compared to large clinical trials. Additionally, because this is a retrospective exploratory analysis with data from electronic medical records, data can be incomplete. Therefore, our analyses of subgroups may be underpowered to robustly demonstrate factors associated with better outcome. Nevertheless, the data presented here provide useful information for clinicians treating lung cancer.

\section{Conclusions}

Nivolumab has improved the 2-year survival rate of patients with progressive advanced NSCLC in our real world cohort significantly to $24 \%$, compared to $14 \%$ with docetaxel (pooled data form CheckMate 017 and 057) (7,9). Given the proven favourable toxicity profile of nivolumab over chemotherapy, the development of checkpoint inhibitors has been one of the great advancements in cancer treatment in the last decades. The results from our study confirm that long term survival rates of patients treated with nivolumab for advanced NSCLC in a real world clinical setting are comparable to survival rates shown in clinical trials.

\section{Acknowledgments}

The authors thank Bristol-Myers Squibb for providing nivolumab to our patients in their Expanded Access Program prior to approval and reimbursement of nivolumab for regular clinical care in the Netherlands.

Funding: None.

\section{Footnote:}

Reporting Checklist: The authors have completed the STROBE reporting checklist. Available at http://dx.doi. org/10.21037/tlcr-19-698

Data Sharing Statement: Available at http://dx.doi. org/10.21037/tlcr-19-698

Conflicts of Interest: All authors have completed the ICMJE uniform disclosure form (available at http://dx.doi. org/10.21037/tlcr-19-698). Prof. Dr. Baas reports grants from BMS, grants from MSD, outside the submitted work. Prof. Dr. Van den Heuvel reports grants from BMS, grants from MSD, grants from Roche, grants from Pfizer, grants from AstraZeneca, grants from Boehringer Ingelheim, outside the submitted work. The other authors have no conflicts of interest to declare.

Ethical Statement: The authors are accountable for all aspects of the work in ensuring that questions related to the accuracy or integrity of any part of the work are appropriately investigated and resolved. This study was conducted in accordance with the Declaration of Helsinki (as revised in 2013) and the guidelines for Good Clinical Practice. Because of the retrospective nature of the research, the requirement for Ethics Board approval and informed consent was waived.

Open Access Statement: This is an Open Access article distributed in accordance with the Creative Commons Attribution-NonCommercial-NoDerivs 4.0 International License (CC BY-NC-ND 4.0), which permits the noncommercial replication and distribution of the article with the strict proviso that no changes or edits are made and the original work is properly cited (including links to both the formal publication through the relevant DOI and the license). See: https://creativecommons.org/licenses/by-nc-nd/4.0/.

\section{References}

1. Brahmer J, Reckamp KL, Baas P, et al. Nivolumab versus docetaxel in advanced squamous-cell non-small-cell lung cancer. N Engl J Med 2015;373:123-35.

2. Borghaei H, Paz-Ares L, Horn L, et al. Nivolumab versus docetaxel in advanced nonsquamous non-small-cell lung cancer. N Engl J Med 2015;373:1627-39.

3. Reck M, Rodríguez-Abreu D, Robinson AG, et al. Pembrolizumab versus chemotherapy for PD-L1positive non-small-cell lung cancer. N Engl J Med 2016;375:1823-33.

4. Herbst RS, Baas P, Kim D-W, et al. Pembrolizumab versus docetaxel for previously treated, PD-L1-positive, advanced non-small-cell lung cancer (KEYNOTE-010): a randomised controlled trial. Lancet 2016;387:1540-50.

5. Mok TSK, Wu YL, Kudaba I, et al. Pembrolizumab versus chemotherapy for previously untreated, PD-L1expressing, locally advanced or metastatic non-small-cell lung cancer (KEYNOTE-042): a randomised, open-label, controlled, phase 3 trial. Lancet 2019;393:1819-30.

6. Planchard D, Popat S, Kerr K, et al. Metastatic non-small cell lung cancer: ESMO Clinical Practice Guidelines for 
diagnosis, treatment and follow-up. Ann Oncol 2018;29 Suppl 4:iv192-237.

7. Horn L, Spigel DR, Vokes EE, et al. Nivolumab versus docetaxel in previously treated patients with advanced non-small-cell lung cancer: two-year outcomes from two randomized, open-label, phase III trials (CheckMate 017 and CheckMate 057). J Clin Oncol 2017;35:3924-33.

8. Gettinger S, Horn L, Jackman D, et al. Five-year followup of nivolumab in previously treated advanced non-smallcell lung cancer: results from the CA209-003 Study. J Clin Oncol 2018;36:1675-84.

9. Vokes EE, Ready N, Felip E, et al. Nivolumab versus docetaxel in previously treated advanced non-small-cell lung cancer (CheckMate 017 and CheckMate 057): 3-year update and outcomes in patients with liver metastases. Ann Oncol 2018;29:959-65.

10. Nabhan C, Klink A, Prasad V. Real-world evidence-what does it really mean? JAMA Oncol 2019;5:781-3.

11. Dudnik E, Moskovitz M, Daher S, et al. Effectiveness and safety of nivolumab in advanced non-small cell lung cancer: The real-life data. Lung Cancer 2018;126:217-23.

12. Areses Manrique MC, Mosquera Martínez J, García González J, et al. Real world data of nivolumab for previously treated non-small cell lung cancer patients: a Galician lung cancer group clinical experience. Transl lung Cancer Res 2018;7:404-15.

13. Schouten RD, Muller M, de Gooijer CJ, et al. Real life experience with nivolumab for the treatment of nonsmall cell lung carcinoma: Data from the expanded access program and routine clinical care in a tertiary cancer centre - The Netherlands Cancer Institute. Lung Cancer 2018;126:210-6.

14. Rittmeyer A, Barlesi F, Waterkamp D, et al. Atezolizumab versus docetaxel in patients with previously treated non-small-cell lung cancer (OAK): a phase 3, openlabel, multicentre randomised controlled trial. Lancet 2017;389:255-65.

15. Kitadai R, Okuma Y, Hakozaki T, et al. The efficacy of immune checkpoint inhibitors in advanced non-small-cell lung cancer with liver metastases. J Cancer Res Clin Oncol 2020;146:777-85.

16. Aso M, Toi Y, Sugisaka J, et al. Association between skin reaction and clinical benefit in patients treated with antiprogrammed cell death 1 monotherapy for advanced nonsmall cell lung cancer. Oncologist 2020;25:e536-44.

17. Shimozaki K, Sukawa Y, Beppu N, et al. Multiple ImmuneRelated Adverse Events and Anti-Tumor Efficacy: RealWorld Data on Various Solid Tumors. Cancer Manag Res 2020;12:4585-93.

18. Sugano T, Seike M, Saito Y, et al. Immune checkpoint inhibitor-associated interstitial lung diseases correlate with better prognosis in patients with advanced non-small-cell lung cancer. Thorac Cancer 2020;11:1052-60.

19. Toi Y, Sugawara S, Kawashima Y, et al. Association of immune-related adverse events with clinical benefit in patients with advanced non-small-cell lung cancer treated with nivolumab. Oncologist 2018;23:1358-65.
Cite this article as: Schouten RD, Egberink L, Muller M, De Gooijer CJ, van Werkhoven E, van den Heuvel MM, Baas P. Nivolumab in pre-treated advanced non-small cell lung cancer: long term follow up data from the Dutch expanded access program and routine clinical care. Transl Lung Cancer Res 2020;9(5):1736-1748. doi: 10.21037/tlcr-19-698 


\section{Supplementary}

Table S1 Definitions of subgroups. Description of the subgroups that were analyzed in this study

\begin{tabular}{|c|c|c|}
\hline Characteristics & \multicolumn{2}{|c|}{ Subgroup definitions } \\
\hline Age & $\begin{array}{l}64 \text { years or younger at start of nivolumab } \\
\text { treatment }\end{array}$ & $\begin{array}{l}65 \text { years or older at start of nivolumab } \\
\text { treatment }\end{array}$ \\
\hline Smoking status & Never smokers & Smokers (former and current) \\
\hline ECOG-PS & $\begin{array}{l}\text { ECOG performance score of } 0 \text { or } 1 \text { at start of } \\
\text { nivolumab treatment }\end{array}$ & $\begin{array}{l}\text { ECOG performance score of } 2 \text { or higher at } \\
\text { start of nivolumab treatment }\end{array}$ \\
\hline Liver metastases & $\begin{array}{l}\text { No radiological evidence of liver metastases } \\
\text { before start of nivolumab treatment }\end{array}$ & $\begin{array}{l}\text { Radiologically proven liver metastases before } \\
\text { start of nivolumab treatment }\end{array}$ \\
\hline $\begin{array}{l}\text { CheckMate } 017 / 057 \text { eligibility [Note: } \\
\text { this variable was excluded from } \\
\text { multivariate analyses due the overlap } \\
\text { with other variables (e.g., ECOG-PS by } \\
\text { definition)] }\end{array}$ & $\begin{array}{l}\text { Patients who would have been excluded from } \\
\text { participation in CheckMate } 017 \text { or } 057 \text { trials, } \\
\text { based on their currently available data }\end{array}$ & $\begin{array}{l}\text { Patients who did not meet any exclusion } \\
\text { criteria for the CheckMate } 017 \text { or } 057 \text { trials } \\
\text { and could have been included in either of } \\
\text { those trials, based on their currently available } \\
\text { data }\end{array}$ \\
\hline Response to prior chemotherapy & $\begin{array}{l}\text { No response (i.e., stable or progressive } \\
\text { disease) to platinum-based chemotherapy } \\
\text { prior to nivolumab treatment, based on } \\
\text { reported outcome of the treating physician }\end{array}$ & $\begin{array}{l}\text { Complete or partial response to platinum- } \\
\text { based chemotherapy prior to nivolumab } \\
\text { treatment, based on reported outcome of the } \\
\text { treating physician }\end{array}$ \\
\hline Treatment-limiting toxicity & $\begin{array}{l}\text { Patients who did not experience (serious) } \\
\text { adverse events leading to discontinuation of } \\
\text { nivolumab. Patients in this group may have } \\
\text { experienced adverse events, but these did } \\
\text { not lead to discontinuation of treatment }\end{array}$ & $\begin{array}{l}\text { Patients who experienced serious adverse } \\
\text { events related to nivolumab that lead to } \\
\text { discontinuation of nivolumab treatment }\end{array}$ \\
\hline
\end{tabular}



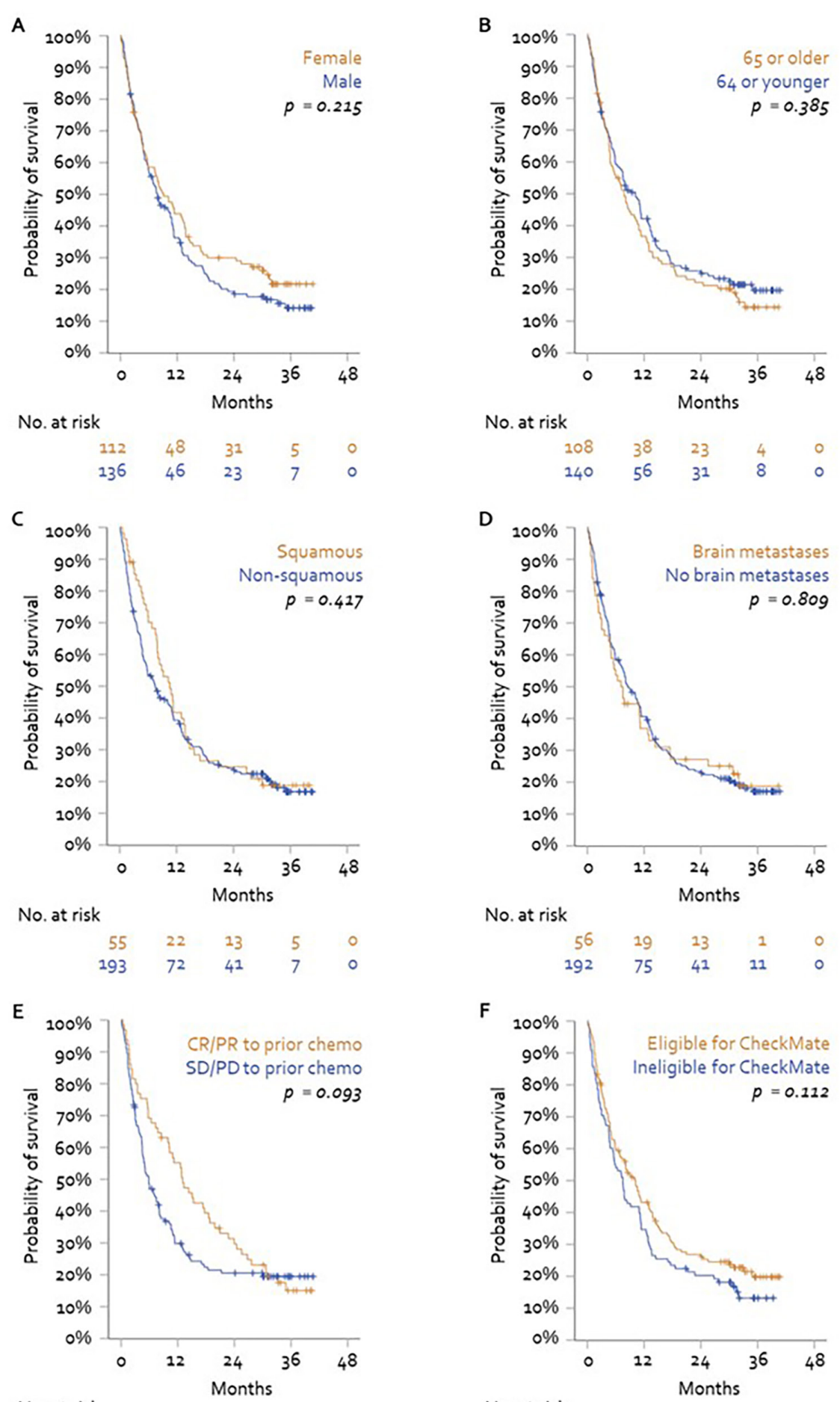

No. at risk
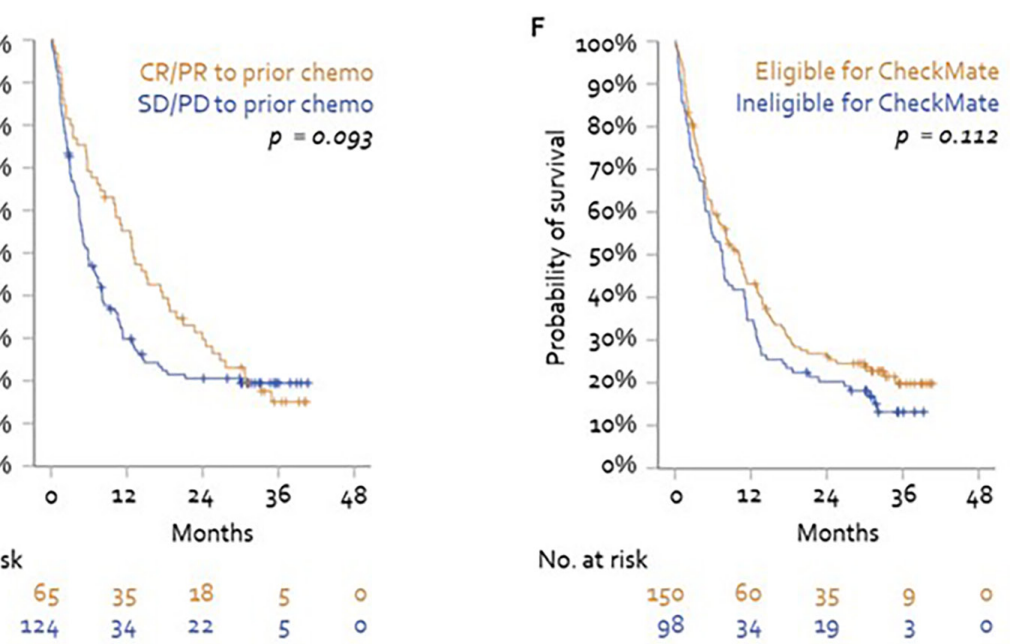

Figure S1 Overall survival of subgroups. Probability of survival for subgroups, estimated by the Kaplan-Meier method. P values and numbers of patients at risk are shown in the figures. No statistically significant differences in OS were observed in subgroups defined by (A) sex, (B) age, (C) tumor histology, (D) radiological evidence of brain metastases before start of nivolumab, (E) objective response to prior platinum-based chemotherapy, or lastly (F) retrospective eligibility for CheckMate 017 and 057. 


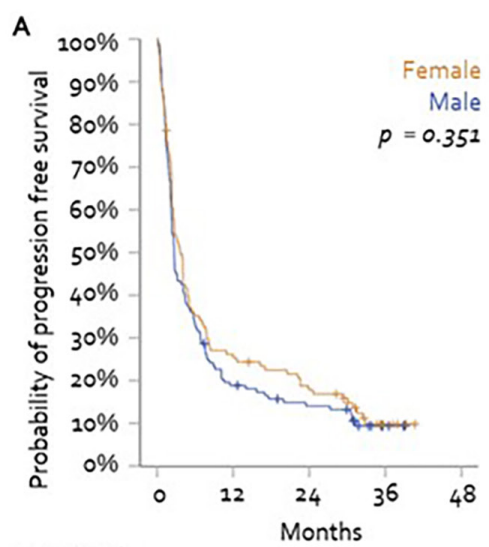

No. at risk
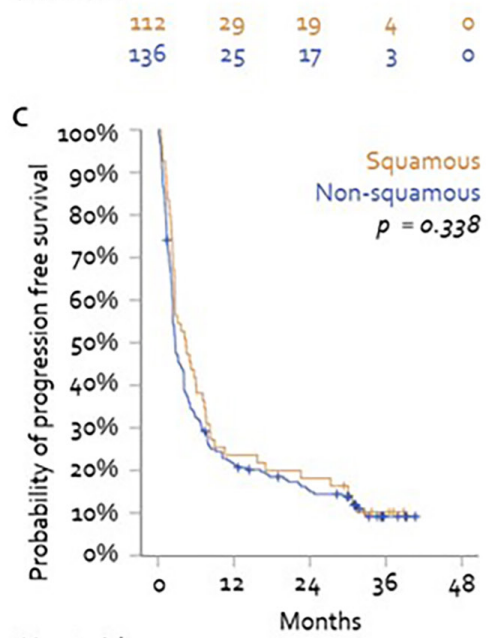

No. at risk
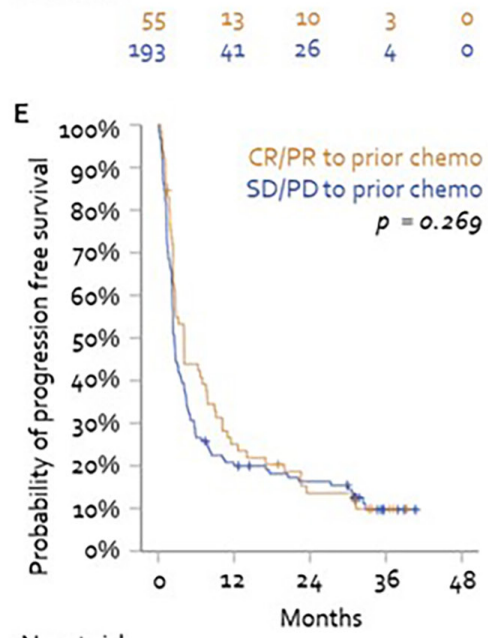

No. at risk

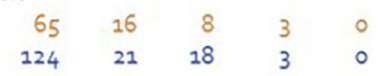

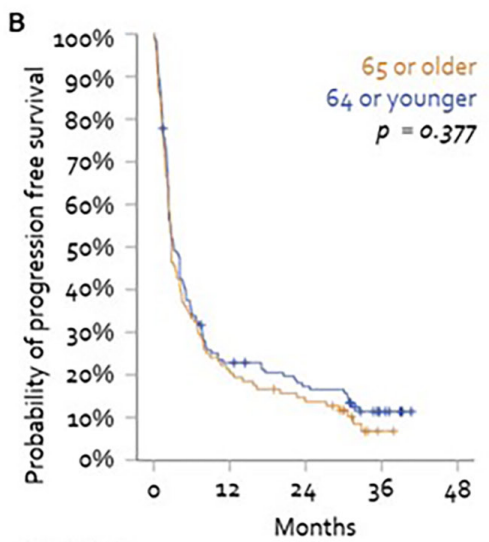

No. at risk
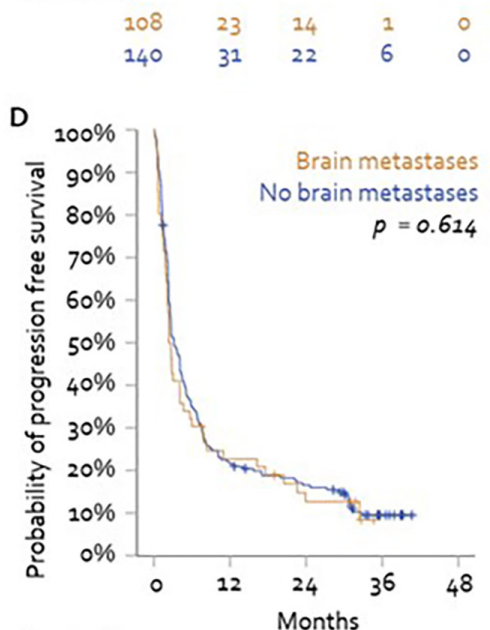

No. at risk
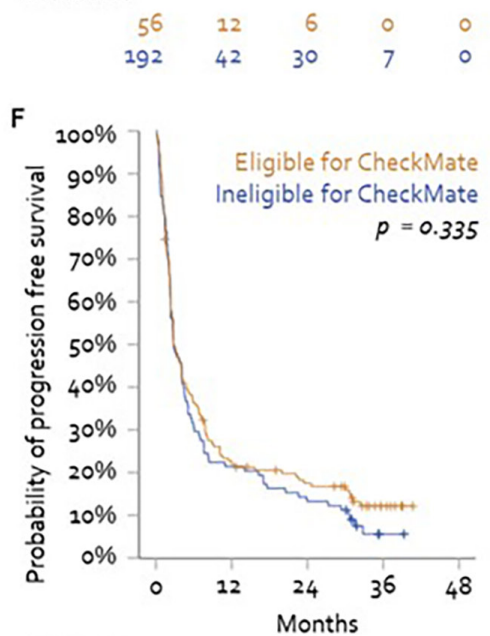

No. at risk

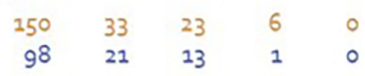

Figure S2 Progression free survival of subgroups. Probability of progression free survival for subgroups, estimated by the Kaplan-Meier method. $\mathrm{P}$ values and number of patients at risk are shown in the figures. No statistically significant differences in PFS were observed in subgroups defined by (A) sex, (B) age, (C) tumor histology, (D) radiological evidence of brain metastases before start of nivolumab, (E) objective response to prior platinum-based chemotherapy, or lastly (F) retrospective eligibility for CheckMate 017 and 057. 